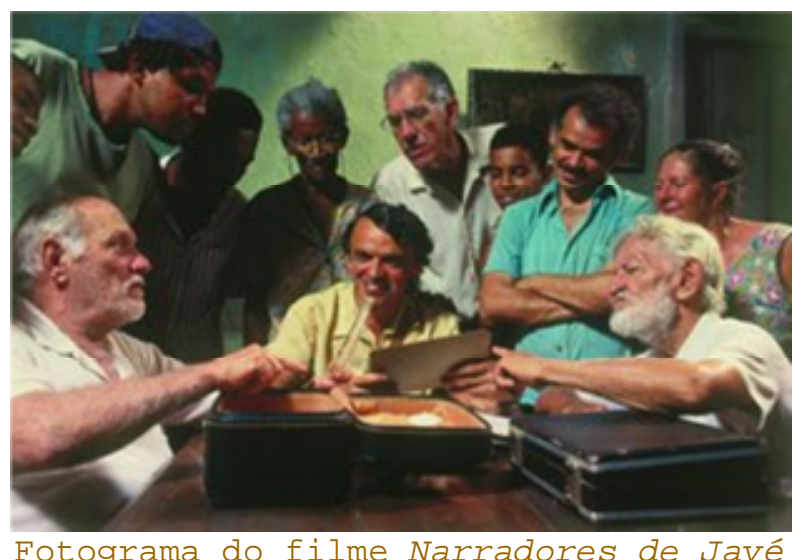

\title{
Narradores de Javé: uma leitura da preservação da memória e da identidade em culturas orais
}

\author{
Carolina Assunção e Alves \\ Carolina Assunção e Alves é jornalista e mestranda em Análise \\ do Discurso da Pós-graduação em Estudos Lingüísticos, na \\ Faculdade de Letras da UFMG.
}

\section{Resumo}

Uma das potencialidades do cinema é a de possibilitar, a partir de uma narrativa ficcional, leituras análogas da realidade. O filme Narradores de Javé, dirigido por Eliane Caffé (2004), revela, entre outras coisas, uma problemática real brasileira: a dificuldade de se conservar a História, a memória e, conseqüentemente, a identidade de grupos sociais fundados na oralidade dos casos contados de geração para geração. O objetivo deste artigo é propor reflexões acerca dessa questão nas culturas sem fontes oficiais e sem registros.

Palavras-chave: memória, identidade e cultura oral. 
Vale de Javé, interior da Bahia. A rotina pacata do pequeno vilarejo é abalada por uma notícia que mudaria definitivamente a vida dos moradores: o povoado seria extinto com a implantação de uma barragem. O "progresso" chegaria ao sertão baiano, trazendo consigo as águas, inundando as ruas daquela cidadezinha, destruindo as casas, a igreja - o espaço de toda a gente que lá estava.

A comunidade reuniu-se para tentar salvar Javé do dilúvio que se anunciava. E a única solução seria transformar o vilarejo em patrimônio histórico, de maneira que ele fosse tombado e, assim, não pudesse ser engolido pelas águas do desenvolvimento. Para o povo de Javé, seria uma tarefa difícil, já que eles não conseguiam visualizar nada que fosse realmente importante e digno de ser eternizado. A única riqueza daquele lugar eram os casos tradicionalmente contados sobre o Vale de Javé - segundo o povo de lá, algo de grande valia. Decidiu-se então fazer um "dossiê científico", um livro que documentasse os grandes e nobres feitos da História do vale. Num espaço habitado por talentosos contadores de história, em sua maioria analfabetos ou semi-analfabetos, quem escreveria tal documento?

o trabalho caberia a Antônio Biá, um malandro de caráter duvidoso, odiado por quase todos devido às traquinagens que já havia cometido. Mas era ele o único de escrita fluente naquelas redondezas. A população de Javé não tinha outra opção, a não ser contar com a letra de Biá. E assim ele ficou encarregado de ouvir morador por morador e registrar a grandiosa história do vilarejo, salvando o povo da inundação e livrando a cidade de ser devorada pelo progresso.

As linhas acima se referem ao filme brasileiro de longametragem Narradores de Javé, um roteiro de Eliane Caffé e Luis Alberto de Abreu, dirigido por Eliane Caffé (2004). 0 argumento inicial para essa produção foi criado a partir da necessidade dos roteiristas e da diretora de descobrir um Brasil escondido pela urbanização e pela modernidade. Como afirma Luis Alberto de Abreu,

é uma viagem a um Brasil que está terminando. O Brasil da oralidade, da riqueza inventiva de suas histórias, da informalidade de suas relações. Um Brasil rural e tradicional, de fortes valores coletivos, que corre o risco de desaparecer sem nenhum registro. (1)

A obra é produto do desejo dos autores de tornar público o cotidiano do interior brasileiro, numa cultura em que a informação e os casos passados de boca em boca não costumam ser considerados fatos históricos nem são valorizados pelos "homens do progresso". Nesse sentido, os autores fizeram expedições pelo interior de Minas Gerais e da Bahia, e 
reuniram casos e histórias da cultura oral que dariam corpo ao filme. Eles partiram de vários fatos reais que, costurados, acabaram por constituir o enredo fictício. Em Narradores de Javé, é marcante a questão da necessidade do registro da informação para que essa seja oficialmente aceita.

Mas a realidade imaginária de Javé não é exatamente uma ficção no âmbito do Brasil. Trata-se de uma realidade comum no país, onde vários projetos para a criação de usinas hidrelétricas têm tornado necessária a destruição de povoados e municípios ribeirinhos, colocando em risco a preservação da memória e, conseqüentemente, da identidade dos moradores desses lugares. - Ministério de Minas e Energia, em parceria com grandes empresas, tem amparado projetos de produção de energia hidrelétrica por meio da construção de barragens fornecedoras. $\mathrm{E}$ os moradores dessas regiões são transferidos para um novo espaço, em troca da destruição de seus lares pelo governo e/ou por grandes empresas interessadas nas usinas hidrelétricas.

Essa troca contribui potencialmente para a destruição da identidade das comunidades que são desalojadas pelos grandes empreendimentos hidrelétricos. As populações dessas cidades são vítimas de uma imposição que as leva a ver a própria terra, a cidade, a vida e as suas recordações, tudo desaparecendo debaixo da água da represa, sem nenhuma possibilidade de defesa. Como conservar a memória da cidade, do povo daquele lugar, numa situação como essa? Como e onde fica a história desses povoados pobres, com moradores pouco instruídos, muitos até analfabetos ou semi-analfabetos? Essas são perguntas facilmente imagináveis, dado que no país há muitos grupos cuja identidade e história ainda se constrói oralmente. Mas encontrar a resposta não apresenta a mesma facilidade, nem é esse o objetivo deste artigo. A proposta aqui é apenas levantar algumas questões relativas à preservação da memória em culturas marcadas pela oralidade, uma vez que não sobram registros para serem lidos e oficialmente considerados.

\section{Um breve histórico}

O advento da escrita, desde as suas formas pré-históricas, passando pela escrita cuneiforme e pela invenção do alfabeto e dos tipos móveis de Gutemberg, até os dias de hoje, tem influência decisiva sobre o hábito do registro na cultura atual. A escrita, como as demais invenções humanas, faz parte de um ciclo que surgiu para satisfazer determinada necessidade, mas acabou por criar demandas complementares àquelas que culminaram em seu aparecimento. Assim, com o passar dos anos, os pictogramas e as gravuras que nasceram para suprir a vontade que o homem tinha de se expressar, 
ganharam novas exigências que levaram a um aprimoramento do sistema de linguagem.

Uma das novas funções adquiridas pela escrita foi a de armazenamento e circulação do conhecimento e da informação, que foram impressos em livros, jornais, panfletos e outros suportes. As bibliotecas foram criadas como espaços que se fizeram necessários para a organização do conhecimento. O homem se deparou com a demanda pelo registro da informação, a fim de que tais bens culturais não se perdessem com o passar do tempo.

O registro e a documentação se tornaram processos inerentes à evolução da sociedade e do homem, que vislumbrou nessa prática, além da preservação do conhecimento já mencionada, uma oportunidade de conservar a própria história e manter viva a memória de tempos remotos. Junto às bibliotecas, os museus e acervos exerciam, e exercem ainda hoje, tal função de guarda e manutenção de informações ou objetos relevantes para a construção histórica de determinada comunidade, estado, país etc.

A necessidade do registro configurou-se como ferramenta de afirmação da identidade, pois o homem habituou-se a reconhecer a própria existência com base na memória. Essa se tornou inseparável da identidade e consolidou uma relação direta com - mundo real. O homem passou a depender do conteúdo presente na memória registrada de seus antepassados para admitir (-se) (n) o presente, como afirmou Santo Agostinho: "Oh, nem sequer chego a compreender a força de minha memória sem a qual não poderia pronunciar meu próprio nome!".(2)

o esforço empenhado no trabalho de preservação da memória ganhou aliados com o avanço da tecnologia. Programas digitais de arquivamento de informações e documentos, assim como aqueles de indexação utilizados em bibliotecas e museus, facilitaram muito a atividade, uma vez que o fato de lidar com papéis sujeitos à ação do tempo (mofo, traças, folhas soltas etc) era bastante complicado.

Contudo, mesmo a simplificação proporcionada pelo fenômeno da tecnologia ainda não conseguiu dar conta de uma questão: a do registro da memória e do conhecimento construídos em culturas marcadas pela oralidade. A história dos grupos sociais que não têm o hábito da escrita, da documentação institucional e oficializante, sobrevive de boca em boca, nos casos contados, nas tradições e nos rituais traçados pela palavra dita e pela linguagem corporal. A dificuldade está em descobrir uma forma de manter vivas essas culturas, já que a cultura ocidental (dominante) é fortemente marcada pela documentação e pela memória institucional. 


\section{Narradores de Javé e a informalidade das narrativas populares}

O problema mencionado acima vem à tona quando visualizamos a possibilidade de extinção de alguma comunidade onde a oralidade é fator central e condutor do dia-a-dia. Os casos do filme Narradores de Javé são exemplos disso. Num vilarejo como Javé, que reflete a realidade de muitas pequenas cidades do sertão brasileiro, a oralidade não é simplesmente uma tradição, é também um traço conjuntural, devido à precária situação sócio-econômica dos moradores quase todos analfabetos. No filme, ao receber a notícia da inundação, os moradores ficaram desesperados, por não possuírem nenhum registro histórico que comprovasse o valor cultural do lugarejo. Por mais que eles conhecessem e soubessem revelar o tesouro de Javé à sua maneira, acabaram reféns da ausência de uma versão oficial documentada.

Para ilustrar como o filme de Eliane Caffé aborda a questão, foram selecionadas duas cenas, uma no início e outra no final da obra. Na primeira, a personagem Zaqueu, interpretada por Nelson Xavier, sugere a seus conterrâneos que eles devem transformar Javé em patrimônio tombado, e esclarece:

porque se Javé tem algo de bom são as histórias de origem, dos guerreiros lá do começo, dos casos que "ocês" vivem contando e recontando. E isso, gente, é história de patrimônio, história grande, acontecimento de fazer arregalar os olhos de morador de muita cidade e capital! (3)

Mas logo completa dizendo que os homens do progresso só aceitam essas histórias se elas estiverem num documento escrito, em trabalho científico. O termo "científico" é definido por Zaqueu como coisa "com sustança da ciência... versada, assim, nas artes e práticas..." (4), e não as "patranha duvidosa" que os habitantes da cidade costumam contar. A partir dessas falas, percebe-se a dificuldade que 0 grupo terá em provar cientificamente algo que não reside em objetos concretos como documentos de memória, que na cultura ocidental globalizada podem ser considerados fatores essenciais para apoiar a manutenção do passado e garantir a permanência da existência humana no presente e no futuro. Não há registro histórico ou de posse de terreno, pois as divisas de Javé foram cantadas e passadas de pai para filho, tudo apenas no dizer. Como então tornar essa história reconhecível, oficial e instituída?

$\mathrm{Na}$ segunda cena, referimo-nos a Antônio Biá (José Dumont), que revela aos moradores o que pensa: para ele, o livro não salvará o povoado da inundação. Biá diz: 
O que nós somos é um povinho desmilingüido que quase não escreve o próprio nome, mas inventa histórias de grandeza pra esquecer a vidinha rala, sem futuro nenhum! E "ocês crê" mesmo que os homens vão parar a represa e o progresso por um bando de "analfabeto"? Não vão, não. Isso é fato. É científico!...

O desabafo de Biá pode dar margem a várias interpretações, dentre elas: 1) ele próprio duvida das histórias que ouviu para registrar no livro e, como não há prova cabal do que foi dito, põe em xeque a credibilidade dos casos passados de geração em geração; 2) ao fazer isso, Biá acredita que todo o esforço de registro será em vão, pois os "castelos de areia" construídos pelos narradores de Javé se desmancharão rapidamente nas águas da hidrelétrica; 3) ao crer que o povo da cidadezinha não terá voz diante dos "homens" que vão construir a represa, ele revela como gente humilde e casos contados oralmente podem ser desvalorizados pela História, pela ciência e pelo desenvolvimento e podem até deixar de existir socialmente; 4) dessa maneira, a personagem coloca em questão a situação de abandono e descrédito em relação à identidade de povos inseridos em culturas marcadamente orais.

\section{A ficção perto do real}

Pensar numa transposição desse enredo fictício de Narradores de Javé para a realidade faz gerar o mesmo tipo de preocupação. Na segunda metade do século XX, no Brasil, a inundação de vilarejos para a construção de represas devastou a história e a identidade de populações como a de Sobradinho e Pilão Arcado, no Nordeste do país. E no interior de Minas, considerado a caixa d'água brasileira por ser o Estado com maior potencial hidrelétrico, a inundação de cidades para a criação de barragens é uma realidade dura vivida hoje por milhares de famílias. Entre junho de 2001 e março de 2004, por exemplo, foi instalada a Usina Hidrelétrica (UHE) de Candonga, construída em parceria pela Companhia Vale do Rio Doce (CVRD) e a Alcan Alumínio do Brasil, com o intuito de represar a água necessária para girar as turbinas da barragem e produzir energia destinada ao consumo exclusivo de indústrias dessas duas gigantes do setor de minérios.

A obra custou quase R\$ 200 milhões e alagou 2,8 quilômetros quadrados de dois municípios da Zona da Mata de Minas Gerais: Rio Doce e Santa Cruz do Escalvado. Nessa segunda cidade, todas as 120 famílias que compunham a comunidade de são Sebastião do Soberbo foram obrigadas a deixar as áreas em que tradicionalmente residiam, para ceder lugar ao lago da hidrelétrica, mudando-se para um núcleo urbano construído pelo consórcio, batizado de "Nova Soberbo". Os moradores de Nova Soberbo reclamam de terem sofrido uma urbanização forçada, já que todos os seus hábitos se modificaram em virtude da estrutura do novo povoado, totalmente diferente da região 
ribeirinha onde viviam. Já foram registrados casos de problemas de saúde, dentre eles depressão e insanidade mental, além da crise financeira causada pela expulsão das populações do próprio lar e pela re-locação dessas pessoas em lugares ainda mais distantes dos grandes centros.

Entre grupos que vivem em locais cujo futuro é ameaçado e cujas culturas são marcadas pela oralidade, é preciso analisar a questão do registro da memória e do conhecimento, para que o risco de desaparecimento desses povos não implique no sumiço de sua memória e sua identidade. Como afirma Marteleto (6), "nas modernas sociedades de massa há um combate pela verdade e em torno da verdade ou ainda, mais apropriadamente, em torno do estatuto da verdade e do papel econômico-político que ela desempenha", e é nesse contexto que se torna coerente uma "aproximação entre a cultura e a informação, ou da cultura como informação". Dentro desse contexto, é possível considerar de fundamental importância a compreensão de como a informação, e por sua vez a cultura, se configuram nos grupos sociais cujas vida e convivência têm seu alicerce na oralidade.

\section{Considerações finais}

Identificar espaços em que os traços caracterizadores da sociedade como informacional - o registro, a documentação, os arquivos, os acervos, a tecnologia etc. - não são evidentes não significa dizer que não haja informação e conhecimento, mas sim que eles estão fixados em uma outra instância, volátil, que é a da oralidade, do boca a boca, o que deve ser especialmente analisado. Isso nos leva a uma necessidade instigante de busca pela qualificação daquilo que pode ganhar - estatuto de memorável, informativo, e logo, constitutivo de identidades sociais nesses grupos específicos.

Sociologia, Antropologia, Arqueologia, História: várias são as Ciências Humanas que se interessam pelas comunidades e pelos grupos sociais nos quais a oralidade é um aspecto marcante. O próprio percurso acadêmico da História Oral, dentro da História, tem semelhanças com os problemas acima abordados. Guarinello propõe que

a história oral é, inevitavelmente, uma zona de fronteira, não tanto entre disciplinas, mas entre a própria academia e o mundo real, entre a memória legítima, cientificamente produzida, dos historiadores, e as memórias individuais, no que têm de pessoal e coletivo. (7)

Os oralistas devem, assim, decidir em que medida podem submeter a memória não-científica às regras da cientificidade, e descobrir qual é a forma legítima de documentar, ao mesmo tempo, as informações obtidas e a sua relação com o objeto/sujeito estudado. 
A História Oral demonstra ser possível defender a pertinência de uma disciplina cujos padrões de coleta e documentação do real não podem ser normatizados. Nesse sentido, poderá auxiliar na qualificação daquilo que poderá ter o estatuto de informacional, memorável e integrante do conhecimento, mesmo num ambiente cujos conteúdos e registros são relegados ao nível da palavra dita, pois a História Oral pretende revelar vozes e segmentos ocultos, centralizando a atenção sobre os dominados, silenciosos e excluídos da História, sobre a história do cotidiano e da vida privada, sobre a história local e enraizada. O povo de Javé, que simboliza os integrantes das comunidades ribeirinhas inundadas para a criação de represas, faz parte desse grupo, enquanto detentor de informação, de conhecimento e de uma memória. Entretanto, a dificuldade está em conservar essa tríade, que para eles é, ao mesmo tempo, tão importante de ser mantida e tão fugidia, pois, como define Nora,

os lugares de memória nascem e vivem do sentimento que não há memória espontânea, que é preciso criar arquivos, que é preciso manter aniversários, (...) porque essas operações não são naturais. E por isso a defesa, pelas minorias, de uma memória refugiada sobre focos privilegiados e enciumadamente guardados nada mais faz do que levar à incandescência a verdade de todos os lugares de memória. Sem vigilância comemorativa, a história depressa os varreria. (8)

\begin{abstract}
One of the cinema's potentialities is the possibility to create, from a fictional narrative, analogue readings of reality. The film Narradores de Javé, directed by Eliane Caffé (2004), reveals, among other things, a real Brazilian problem: the difficulty in conservating History, memory and, as a consequence, the identity of social groups founded on oral tales told from generation to generation. The aim of this article is to propose reflections on this question in cultures without official sources or registers.
\end{abstract}

Key-words: memory, identity and oral culture.

\title{
Notas
}

(1) Esclarecimentos sobre o roteiro do filme disponíveis no site oficial de Narradores de Javé. http://www. narradoresdejave.com.br.

(2) AGOSTINHO apud FERNANDES, 2004. p. 118.

(3) ABREU e CAFFÉ, 2004, p. 21.

(4) ABREU e CAFFÉ, 2004, p. 26.

(5) ABREU e CAFFÉ, 2004, p. 161. 
(6) MARTELETO, $1994, \mathrm{p} .121$.

(7) GUARINELLO, 1998, p. 63.

(8) NORA, 1993, p. 13.

\section{Bibliografia}

ABREU, L. A., CAFFÉ, E. Narradores de Javé: roteiro - 17a versão. São Paulo: Imprensa Oficial do Estado de São Paulo, 2004.

AMADO, Janaína, FERREIRA, Marieta de Moraes (orgs). Usos e abusos da história oral. Rio de Janeiro: Editora da Fundação Getúlio Vargas, 1998.

BAUMAN, Zygmunt. Comunidade: a busca por segurança no mundo atual. Rio de Janeiro: Jorge Zahar, 2003.

BAUMAN, Zygmunt. Globalização: as conseqüências humanas. Rio de Janeiro: Jorge Zahar, 1999.

DVD Narradores de Javé. $102 \mathrm{~min}$. NTSC Cor. Produzido e distribuído por Videolar S.A., de Manaus, sob licença de Videofilmes Produções Artísticas LTDA, 2005 .

FERNANDES, Geni Chaves. A ameaça: tempo, memória e informação. Tese (Doutorado em Ciência da Informação) - Universidade Federal do Rio de Janeiro - UFRJ. Rio de Janeiro: 2004.

FERREIRA, Marieta de Moraes. Desafios e dilemas da história oral nos anos 90: o caso do Brasil. In: História Oral - revista da Associação Brasileira de História Oral, número 1, p. 19-30, junho de 1998. Recife: Associação Brasileira de História Oral.

GUARINELLO. Breve arqueologia da história oral. In: História Oral - Revista da Associação Brasileira de História Oral, número 1, p. 61-65, junho de 1998. Recife: Associação Brasileira de História Oral.

MARTEleto, Regina Maria. Cultura da modernidade: discursos e práticas informacionais. In: Revista da Escola de Biblioteconomia da UFMG, volume 23, número 2, p. 115-137, 1994. Belo Horizonte: Escola de Ciência da Informação.

NORA, Pierre. Entre memória e história: a problemática dos lugares. In: Projeto História: revista do Programa de Estudos Pós-graduados em História e do Departamento de História da PUC-SP. São Paulo: Educ, p. 7-28, 1993.

THOMPSON, Paul. A voz do passado - história oral. Rio de Janeiro: Paz e Terra, 1998. 